\title{
Climate-growth relationships at the transition between Fagus sylvatica and Pinus mugo forest communities in a Mediterranean mountain
}

\author{
Chiara Calderaro $^{1} \cdot$ Claudia Cocozza $^{2} \cdot$ Caterina Palombo $^{1} \cdot$ Bruno Lasserre $^{1} \cdot$ Marco Marchetti $^{1}$. \\ Roberto Tognetti ${ }^{3,4}$ (D)
}

Received: 23 December 2019 / Accepted: 19 May 2020 / Published online: 17 June 2020

(C) INRAE and Springer-Verlag France SAS, part of Springer Nature 2020

\begin{abstract}
- Key message Species interactions implicate a complex balance of facilitation and competition, which may shift during community development, thus structuring the subalpine ecotone of Mediterranean mountain ranges through time and space. This study highlights that encroachment of grasslands and simultaneous downward/upward movement of forest tree species involve species interferences and environmental feedbacks, with differential effects on mountain pine and European beech, and the grassland communities of the Majella Massif.

- Context The transitional ecotone from the European beech closed forest to the mountain pine krummholz vegetation in the Majella Massif (Apennines, Italy) is a sensitive area to climate and land-use changes. Vegetation shifts in these ecotonal zones may cause a negative impact on the spatial distribution and survival of rare or endemic herbaceous species, thus influencing the appearance, structure, and productivity of the subalpine ecotone of the Majella National Park.

- Aims We focused on determining the structures and dynamics of this Mediterranean tree line, and the climate-growth relationships of European beech and mountain pine. We investigated the upward and downward movement of pine into areas potentially suitable for beech expansion, and the concurrent beech encroachment upward.

- Methods Growth dynamics and canopy cover of European beech closed forest and mountain pine krummholz vegetation were analyzed in relation to disturbances at four different sites.

- Results Spring and summer temperatures and summer precipitation affected stem radial growth of both species. In details, spring and summer temperatures negatively affected tree ring width (TRW) of European beech, except for the highest site, whereas spring temperatures affected positively and summer temperatures negatively TRW of mountain pine. Mountain pine expanded upward, encroaching formerly grazed pastures and harvested areas, especially where the soil is shallow and rocky; downward expansion is
\end{abstract}

Handling Editor: Céline Meredieu

Contribution of the co-authors All authors participated to the conceptualization, the methodology, and the reviewing; Chiara Calderaro and Caterina Palombo collected the samples, made the analysis, examined the data, and wrote the original draft; Claudia Cocozza examined the data and edited the original draft; Bruno Lasserre supervised the analysis and examined the data; Marco Marchetti was responsible for funding acquisition and forest management advice; Roberto Tognetti supervised the research, realized the investigation, and wrote the paper.

Roberto Tognetti

tognetti@unimol.it

1 Dipartimento di Bioscienze e Territorio, Università degli Studi del Molise, Contrada Fonte Lappone s.n.c, 86090 Pesche, Italy

2 Dipartimento di Scienze e Tecnologie Agrarie, Alimentari Ambientali e Forestali, Università degli Studi di Firenze, Via San Bonaventura 13, 50145 Florence, Italy
3 Dipartimento di Agricoltura, Ambiente e Alimenti, Università degli Studi del Molise, Via Francesco De Sanctis s.n.c, 86100 Campobasso, Italy

4 The EFI Project Centre on Mountain Forests (MOUNTFOR), Via Edmund Mach 1, 38010 San Michele a/Adige, Italy 
also occurring, following progressive abandonment of forest management practices. At the same time, European beech recruitment is moving upward, interspersed within mountain pine krummholz, taking advantage from canopy shelter and higher temperature.

- Conclusion Climate and land-cover simultaneous changes induce species interactions and a complex balance of facilitation and competition, which may shift during community development and structure the subalpine European beech-mountain pine ecotone of the Majella Massif through time and space.

Keywords Disturbance indicators $\cdot$ European beech $\cdot$ Land cover $\cdot$ Mountain pine $\cdot$ Vegetation shift $\cdot$ Tree line

\section{Introduction}

The average global temperature on Earth has increased by about $0.8^{\circ} \mathrm{C}$ since 1880 (NOAA 2019). Climate change scenarios predict an increase in the mean global temperature in the range of $0.3-4.8{ }^{\circ} \mathrm{C}$ in 2100 relative to mean values in 1986-2005 (IPCC 2013). Warming temperatures have a substantial effect on montane forest ecosystems (Rangwala and Miller 2012). Indeed, temperature in the growing season broadly drives the position of upper tree and forest lines (Körner and Paulsen 2004). Since the upper altitudinal limit of tree establishment occurs at elevation, where the mean temperature of the growing season is about $6.4^{\circ} \mathrm{C}$, rising temperatures will potentially enable many tree species to establish at higher elevations (Walther et al. 2005; Lenoir et al. 2008). High-altitude forests provide proxy records for climatic changes at various temporal and spatial scales, and are investigated to determine the influence of climate variability and the sensitivity to warming temperature on tree growth and forest productivity (Cazzolla Gatti et al. 2019; Alvites et al. 2019).

On a local scale, many mountain regions have experienced agricultural land abandonment, adding to warming and leading to enhanced seedling survival and decreased mortality from grazing (Speed et al. 2010; Cudlín et al. 2017). The impact of landcover changes on altitudinal tree line dynamics has been particularly important in areas with a long history of intense anthropogenic influence, such as the European mountains (Batllori et al. 2010; Palombo et al. 2014a; Améztegui et al. 2016; Treml et al. 2016). Besides, environmental disturbance interrelates with temperature trend and land use, driving regeneration dynamics of forests by creating opportunities for the establishment of new tree individuals (Chauchard et al. 2010; Tognetti and Palombo 2013). This may cause variability in the direction and rate of shifts in composition and functioning of contiguous communities, facing environmental changes. Indeed, whether the variability in response results in species exclusion or coexistence will depend upon how species differ in their ability to adapt to environmental changes. Unfortunately, the relative importance of species resilience and sensitivity to changes in environmental conditions at the tree line is poorly understood, particularly in Mediterranean mountains.

At the tree line ecotone, in the Swiss Alps, Gehrig-Fasel et al. (2007) observed that land abandonment was the most dominant driver for the establishment of new forest areas, though some of the upward shift was attributed to warming temperatures. In these Alpine environments, European beech (Fagus sylvatica L.) reaches the tree line, in the southernmost parts, whereas, the dominant tree line species are conifers, including mountain pine (Pinus mugo Turra ssp. mugo) in some regions in the East. The latter species dominates the tree line of the north-eastern Calcareous Alps in Austria, forming a shrubby krummholz belt (Dullinger et al. 2005). Larix decidua Mill., Pinus cembra L., and Picea abies (L.) Karst., and locally mountain pine, are also the dominant species in the Italian Alps. Conversely, in the Italian Apennines, the European beech timber line has a compact frame due to anthropogenic origin (e.g., grazing, burning, logging) (Pezzi et al. 2007), while the krummholz belt dominated by mountain pine is an exception (Stanisci et al. 2005). In Mediterranean mountains, overall, our understanding of how climate and land-cover changes influence vegetation shifts along the altitudinal gradient, from the closed forest to the meadow zone, is still poor (Camarero et al. 2006; Piermattei et al. 2012).

In central Apennines, where the chain reaches its maximum elevation, predicted climate warming is likely to shift range margins of European beech upslope, but only if populations of European beech are resilient to the harsh environment and able to invade the resident krummholz belt. European beech is a late-successional shade-tolerant species, to which the pioneer light-demanding mountain pine may provide shelter against frost temperatures, strong winds, and browsing herbivores. However, late spring frost may cause a decrease in European beech productivity, particularly at elevations in the range 1500-1700 $\mathrm{m}$ a.s.l., on steep slopes and north aspects of the central Apennines (Bascietto et al. 2018). Therefore, a question arises on whether environmental changes may trigger differences between these two species in community feedbacks and range dynamics (Dullinger et al. 2005). Since global warming may interact locally with land-use changes, shifts in tree line and changes in tree growth at high elevation mountain forests may act as early indicators of landscape and ecosystem responses to environmental changes in sensitive areas, such as the Mediterranean region. Therefore, these ecotonal indicators may add insights on regional-specific sensitivity to climatic variation and species-specific movement in bordering communities (Harsch et al. 2009; Gottfried et al. 2012). 
In the Majella Massif (central Apennines), mountain pine reaches the southern edge of its latitudinal distribution range. Growth of mountain pine in this area is particularly affected by temperature at the start and end of the growing season, but also by summer precipitation (Palombo et al. 2014b). Nevertheless, summer pastoralism legacy and seed dispersal trend, more than climate factors, have influenced mountain pine krummholz dynamics (Dai et al. 2017). In the same area, the canopy cover of European beech has increased from 1975 to 2003, as detected by mid-resolution satellite imagery (van Gils et al. 2008). Nevertheless, minimum temperatures and the phenological stage of the trees may impact European beech productivity in the Apennines, depending on both altitude and exposure of the stands (Nolè et al. 2018; Allevato et al. 2019). Therefore, it is not clear whether the cessation of grazing activities and the increase of air temperature are favoring mountain pine, expanding it toward both higher and/or lower altitudes in areas suitable for the development of European beech (competitive effects), or if the nursing protection of krummholz patches provides benefit on growth performance of European beech (facilitative effects), for moving upward.

In this study, we focused on vegetation dynamics and growth rates of pine and beech across the subalpine ecotone between the closed forest (European beech) and the krummholz zone (mountain pine) in the Majella Massif. Based on the above considerations, we derived the following hypotheses: (i) environmental changes increase spatial and temporal dynamics of mountain pine with facilitation effects on European beech, mainly at higher elevation; (ii) competition effects of mountain pine on European beech may prevail, enhanced by earlier onset of the growing season and increasing risk of late frost damage, and warming temperature, particularly at lower elevation. To test these hypotheses, we analyzed the effects of climate and disturbance on the radial growth of mountain pine and European beech at the transition from the beech closed forest to the pine krummholz zone. Vegetation dynamics were also determined in four different sites through aerial photographs from 1954 to 2017. The objectives of this study were as follows: (i) to analyze the climatic response of European beech and mountain pine in this ecotone, (ii) to reconstruct the disturbance history of the studied forest ecotone, (iii) to disentangle the influence of climate and disturbance on radial growth patterns and tree vegetation dynamics of the European beech and mountain pine tree-line system.

\section{Materials and methods}

\subsection{Study area}

The Majella Massif is located in the Majella National Park (MNP) in central Italy, about $30 \mathrm{~km}$ inland from the Adriatic
Sea. The Majella Massif has an overall area of $11 \mathrm{~km}^{2}$ above $2500 \mathrm{~m}$ a.s.l., with 27 peaks over $2000 \mathrm{~m}$ and the highest summit (Monte Amaro) reaching $2794 \mathrm{~m}$ a.s.l. (Stanisci et al. 2005). Quaternary glaciations in the Majella Massif were typified by an extended ice cap (about $30 \mathrm{~km}^{2}$ ), which covered the higher portion of the chain (Catonica and Manzi 2002). This high-altitude plateau, broadly sharing the main vegetation of the high-altitude central Apennines, exhibits some peculiar floristic characteristics, suggesting a different background to the Quaternary development of its vegetation (Blasi et al. 2005). The research area has a montane climate, with snowy winters and relatively moist summers (Van Gils et al. 2008). Mean annual temperature in the period 1932 2010 was $10.2{ }^{\circ} \mathrm{C}$, and mean total annual precipitation in the period 1920-2010 was $1140 \mathrm{~mm}$ (Palombo et al. 2014a). The elevational bioclimatic gradient of the Majella Massif ranges from Mediterranean through sub-Mediterranean biome to temperate-montane and arctic-alpine biome.

\subsection{Sampling sites}

Temporal and spatial evolution of mountain pine krummholz and European beech forest was studied in four different sites from 1954 to 2017 (Fig. 1), mapping sites in geographic information system (GIS) (Fig. 2). The most representative areas of the transition zone between the two communities were selected in 1954, by aerial images of the "Volo Base IGM 1954/56," Geographical Military Institute (Italy); in 1996, by aerial images of "Volo Parco Scientifico e Tecnologico d'Abruzzo 1996" (available on Geoportal of Abruzzo region); and in 2017 , by web platform at international level (Google Earth).

To study land-cover changes, a circular area of $200 \mathrm{~m}$ in diameter was marked in each site, with the center established between pine krummholz and beech forest, considering the shifting of $3 \mathrm{~m} \mathrm{year}^{-1}$ of mountain pine (Palombo et al. 2013) and the time span between 1954 and 2017 (to include the ecotone in the area of photointerpretation) (Fig. 2). The four study sites were located at different altitudes and exposures at the subalpine ecotone, and they represent stands with different age structures and without recent human impacts. The site Pescofalcone (PE_E $14^{\circ} 04^{\prime} 45.3426$; N $42^{\circ} 07^{\prime}$ 26.8507) is located on the northeastern slope of Monte Pescofalcone, in the Oriented Natural Reserve of Orfento Valley, at $2127 \mathrm{~m}$ a.s.l.; the site Ugni (UG-E 14 9' 35.02; $\mathrm{N} 42^{\circ} 09^{\prime} 10.4618$ ) is located on the northern slope of Monte Ugni, in the Oriented Natural Reserve of Feudo Ugni, at 1935 $\mathrm{m}$ a.s.1.; the site Piana Grande (PG-E $14^{\circ} 06^{\prime} 17.7145 .32$; N $\left.42^{\circ} 08^{\prime} 49.5394\right)$ is located on the southwestern slope of the uplands of "Majelletta," in the Oriented Natural Reserve of Orfento Valley at $1895 \mathrm{~m}$ a.s.l.; the site Blockhaus (BK-E $14^{\circ} 07^{\prime} 34.2510 ; \mathrm{N}^{\circ} 02^{\circ} 10.4618$ ) is located along the 


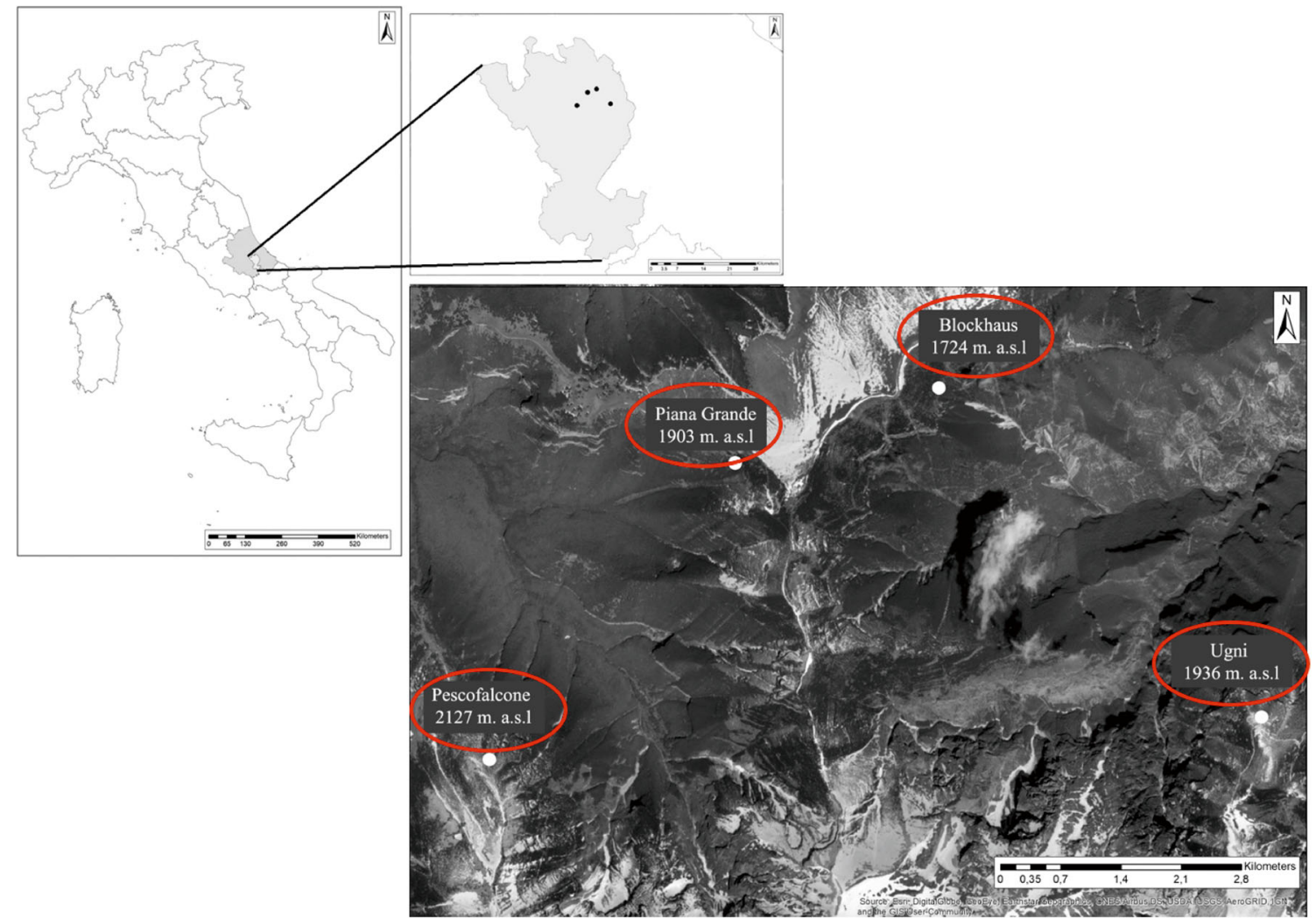

Fig. 1 Location and altitude of four study sites (PE-Pescofalcone, UG-Ugni, PG-Piana Grande, BK-Blockhaus - white dots) in the Majella National Park

southeastern slope of the large pastures of "Majelletta" at 1770 $\mathrm{m}$ a.s.l.

To study tree growth patterns, sampling was performed in four different circular areas, with a $40-\mathrm{m}$ diameter and the geometric center established on the transition zone between beech closed forest and pine krummholz zone. In each site, trees were selected to maximize the temporal and spatial extent of the time series and georeferenced in GIS environment (Fig. 2; contour lines visually represent changes over time in the spatial patterns of forest vegetation and species composition within the sampling areas). Their positions in the four sampling sites were recorded to show vegetation shift and temporal evolution of the two forest types.

In temperate Europe, European beech is one of the most important and widespread broadleaved species (Houston Durrant et al. 2016), particularly sensitive to changes in spring temperature regimes. In Alpine environment, mountain pine is the most tolerant species to cold temperature and bedrock lithology among the European pines (Ballian et al. 2016). In the Majella National Park, mountain pine grows at the southern limit of its distribution range and krummholz patches represent differentially permeable barriers to European beech. Accordingly, we shed light on the interactive effects of simultaneous spatial and temporal factors on community structure and vegetation dynamics of the transitional subalpine ecotone between European beech forest and mountain pine krummholz.

\subsection{Tree rings}

The age classes of trees were determined through dendrochronological analysis. Two woody cores were collected at $120^{\circ}$ from each other, using a $0.5-\mathrm{cm}$ diameter increment borer, on 20 co-dominant or dominant trees of each species. The prostrate habit of mountain pine results in a dense and impenetrable cover mat over the whole area; the main difficulty was to distinguish individual stems from the branches. Mountain pine trees were cored close to the base of the trunk and on the cross-slope side of the trunk to avoid sampling on branches and compression wood (Palombo et al. 2018). European beech trees were sampled at breast height $(1.3 \mathrm{~m})$. Diameter at breast height (DBH) and tree height were measured only for European beech trees with a DBH $>9 \mathrm{~cm}$ (Table 1). Tree cores were mounted on woody supports, air dried and sanded, following standard dendrochronological procedures (Schweingruber 1988). Tree-ring widths (TRW) were measured with a $0.01-\mathrm{mm}$ resolution with LINTAB measurement equipment, coupled to a stereomicroscope $(\times$ 60 magnification; Leica, Germany) and time series analysis program TSAP Win (Frank Rinn, Heidelberg, Germany). Raw TRW chronologies of each tree were statistically crossdated using COFECHA program (Holmes 1983). Eight raw TRW chronologies, two for each site, were obtained: four for European beech and four for mountain pine. 

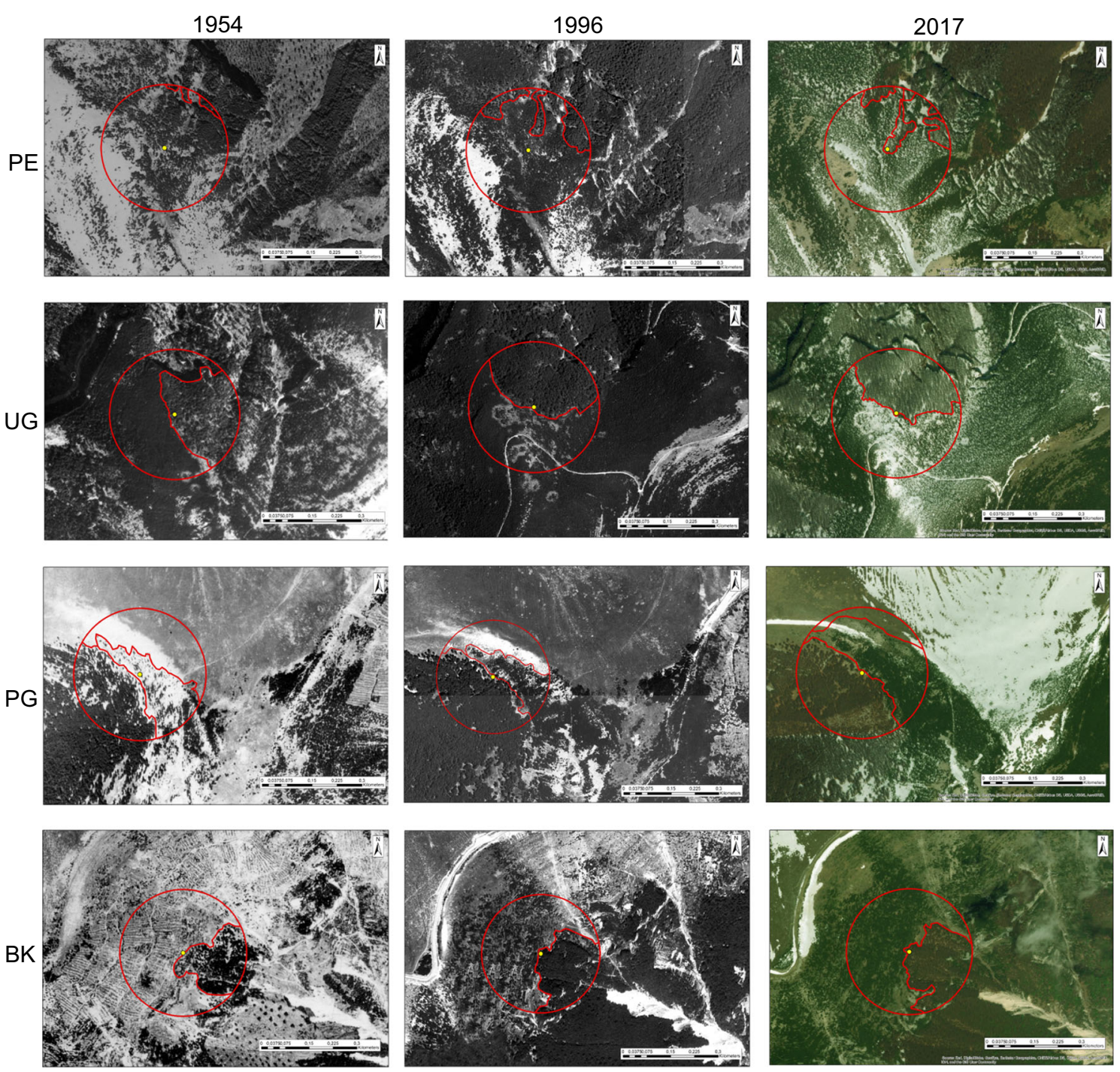

Fig. 2 The transitional ecotone from the European beech closed forest to the mountain pine krummholz vegetation in the Majella Massif. Diachronic analysis on aerial photos carried out in 1954, 1996, and 2017 originated from aerial images of the "Volo Base IGM 1954/56," Geographical Military Institute (Italy), aerial images of "Volo Parco Scientifico e Tecnologico d'Abruzzo 1996" and 2017 available from WEB platforms at international level (Google Earth). Because environmental conditions change with increasing elevation, the

The individual chronologies were standardized in $\mathrm{R}$ environment (R Foundation for Statistical Computing, Vienna, Austria), producing ring width index chronologies of each tree species in each study site. In order to remove age-related trends and non-climatic noise in raw TRW chronologies, individual-based detrending model, using a spline function with a $30 \%$ frequency variability cut-off at 15 years, was applied to all trees of both species, producing standardized chronologies (RWI).

Descriptive statistics were used to compare chronologies: mean ring width (MRW); standard deviation (SD), which estimates the variability of measurements for the variation in spatial patterns between beech forest and pine krummholz in the circular areas of $200 \mathrm{~m}$ in diameter marked in each site (with the center established between pine krummholz and beech forest) can be visually represented. The transition from beech forest (light color) to pine krummholz (dark color) is determined by changing growing conditions, resulting in in spatial separation between the two vegetation types

whole series; mean sensitivity (MS), which is an indicator of the mean relative change between consecutive ring widths and calculated as the absolute difference between consecutive indices divided by their mean value; mean inter-series correlation (Rbar), which is a measure of the common variance between the single series in a chronology and series (Briffa 1995); first-order serial autocorrelation (AC), which quantifies the temporal persistence in growth among consecutive years, measuring the persistence retained before and after standardization; expressed population signal (EPS), which measures the signal strength, such as the amount of climatic information 
Table 1 Age structure (including medium and maximum age of European beech and mountain pine) and time span in PEPescofalcone, UG-Ugni, PGPiana Grande, BK-Blockhaus

\begin{tabular}{lllll}
\hline Site & Pescofalcone & Ugni & Piana Grande & Blockhaus \\
\hline Medium age beech (years) & 72 & 84 & 71 & 68 \\
Maximum age beech (years) & 95 & 102 & 118 & 92 \\
Time span (beech) & $1918-2012$ & $1911-2012$ & $1896-2013$ & $1921-2012$ \\
Medium age pine (years) & 69 & 68 & 50 & 54 \\
Maximum age pine (years) & 100 & 98 & 83 & 75 \\
Time span (pine) & $1914-2013$ & $1916-2013$ & $1931-2013$ & $1940-2014$ \\
\hline
\end{tabular}

included in the developed chronologies (Wigley et al. 1984). The EPS quantifies the degree to which a particular sample chronology portrays a hypothetically perfect chronology and, considering the inter-series correlation and the sample size, estimates how well a finite number of samples represent the theoretical population mean. An EPS $>0.85$ is considered an acceptable threshold for statistically reliable chronologies (Wigley et al. 1984). Higher values of MS and higher SD are indicative of climatic effects on the chronologies. Mean standardized chronologies were used to analyze climate-growth relationships.

\subsection{Climate-growth relationships}

Climatic data (maximum and minimum monthly temperature and total monthly precipitation) of the period 1901-2013 were derived from the CRU TS 3.1 gridded data set, with $0.5^{\circ}$ spatial resolution (Mitchell and Jones 2005), and used for comparison with tree-ring records. Significant correlation coefficients were obtained between monthly observations of the CRU data set and monthly climatic data recorded by the three local meteorological stations in the study area (Pescocostanzo, Sant'Eufemia a Majella, and Caramanico) (Palombo et al. 2014b). Averaged climatic data from the four grid points in the study area were selected.

Climate-growth relationships were assessed using the treeclim package (Zang and Biondi 2013) in the R environment (R Foundation for Statistical Computing, Vienna, Austria). A linear model was fitted to seasonal temperature and summer precipitation. The climate-growth relationships (tree-ring chronologies and monthly climatic data) were examined using correlation function (CF) analysis, and moving $\mathrm{CF}$ (MCF) analysis was performed to detect the stationarity and consistency of CFs over time. The CFs were separately calculated in each month, from March of the previous year to October of the current year, in the period 1901-2013. Climatic data from March of the previous year $(t-1)$ to October of the current year $(t)$ were used as independent variables, whereas standardized mean RWI in the four sampling sites were used as dependent variables. The MCF analysis was repeatedly performed for consecutive time windows of chronologies to investigate the temporal stability of their main climatic signals. Correlation coefficients were always between -0.5 and 0.5 . Coefficients of 0.5 and -0.5 indicate positive and negative correlation between $x$ - and $y$-values, respectively. Treeclim assessed the statistical significance of the correlation coefficients through a bootstrap process (Guiot 1991).

\section{Results}

\subsection{Land-cover changes}

Land cover (\%) in 1954, 1996, and 2017 was extracted in the four sampling sites (Table 2). Overall, forest cover varied over time and across sites (Fig. 2). In PE, the highest site, land cover varied from 2 to $13 \%$ for European beech and from 98 to $87 \%$ for mountain pine, between 1954 and 2017. Mountain pine formed a dense krummholz. Beech trees grew above their altitudinal limit (2127 $\mathrm{m}$ a.s.1.), within the pine krummholz. In UG, land cover remained relatively constant, between 1954 and 2017, with a percentage of about $40 \%$ for European beech and $60 \%$ for mountain pine. Mountain pine is currently suffering from fungal disease that causes tree mortality. European beech took advantage from the sheltering canopy of mountain pine and expanded toward higher elevation. PG is characterized by an abundant recolonization of mountain pine, especially in those clearings, where grazing was once practiced. Mountain pine and European beech stands are distant from each other. Young European beech trees established within the pine krummholz; land cover varied from 37 to $49 \%$ for beech and from 26 to $41 \%$ for pine, between 1954 and 2017. The open area is characterized by beech recruitment and abundant pine seedlings, especially on rocky and sunny soils. In $\mathrm{BL}$, in the $1950 \mathrm{~s}$, mountain pine was completely cut to produce charcoal. Here, abundant mountain pine recruitment is present in abandoned grazing areas. European beech expanded upward, but only to a certain extent; land cover varied from 
Table 2 Geoportal of Abruzzo region and orthophotos of 2017 available on WEB platforms at international level (Google Earth). Land cover (\%) in 1954, 1996, and 2017 in PE-Pescofalcone, UG-Ugni, PGPiana Grande, BK-Blockhaus

\begin{tabular}{lllll}
\hline Site & Species & 1954 & 1996 & 2017 \\
\hline PE & F. sylvatica & $2 \%$ & $15 \%$ & $13 \%$ \\
& P. mugo & $98 \%$ & $85 \%$ & $87 \%$ \\
UG & F. sylvatica & $40 \%$ & $44 \%$ & $40 \%$ \\
& P. mugo & $60 \%$ & $56 \%$ & $60 \%$ \\
PG & F. sylvatica & $37 \%$ & $50 \%$ & $49 \%$ \\
& P. mugo & $26 \%$ & $23 \%$ & $41 \%$ \\
BK & F. sylvatica & $26 \%$ & $34 \%$ & $32 \%$ \\
& P. mugo & $74 \%$ & $66 \%$ & $68 \%$ \\
\hline
\end{tabular}

26 to $32 \%$ for beech and from 74 to $68 \%$ for pine (between 1954 and 2017).

\subsection{Tree-ring chronologies and age structure}

European beech stands in PE, PG, and BK include uneven aged and unthinned stands (the national park was established in 1991). In UG, even aged and old coppice structures were confirmed by the high number of stumps (31) and trees (247) per ha (Table 3). In PG, low numbers of stumps (5) and trees (8) per ha were evident (Table 3). The mean height of European beech ranged between 11.5 and $14.5 \mathrm{~m}$ in UG, $\mathrm{PG}$, and $\mathrm{BK}$, whereas it reached $4 \mathrm{~m}$ in PE, where extreme climatic conditions influence tree growth (Table 3). In PE, European beech trees showed an average age similar to BK, with MRW increment of $0.5 \mathrm{~mm}_{\text {year }}{ }^{-1}$ and a maximum DBH of only $8 \mathrm{~cm}$.

The maximum age of European beech was 95, 102, 118, and 92 years in PE, UG, PG, and BK, respectively (Table 4). In European beech, increasing TRW trend generally occurred at all sites, except PE, where decreasing TRW trend appeared. European beech showed values of MRW of 1.274, 1.228, and 1.072 in BK, UG, and PG, respectively, whereas MRW was 0.468 in PE, the site at the highest altitude. European beech showed mean inter-series correlations of standardized chronologies with $r=0.454$ (PE), $r=0.487$ (UG), $r=0.558$ (PG), and $r=0.497$ (BK). Statistical cross-dating between standard chronologies showed high EPS values $(>0.85)$ in each site (Table 4). The highest values of MS were found in PE and BK (0.400 and 0.385 , respectively).

In mountain pine, several cores presented missing rings or density fluctuations. Mountain pine showed the longest chronologies in PE and UG (100 and 98 years) (Table 4), since 1914 and 1916, respectively; the shortest chronologies were in PG and BK (83 and 75 years), since 1931 and 1940, respectively. MRW spanned from $0.621 \mathrm{~mm}^{-1}$ year $^{-1}$ in PE, the minimum values, to $0.820 \mathrm{~mm}$ year $^{-1}$ in $\mathrm{PG}$, the maximum value, with common trends. EPS values close to the threshold value of 0.85 , except for UG, were obtained (Table 4). Mountain pine exhibited significant mean correlation coefficients $(P<$ 0.001 ) in all plots and mean inter-series correlations in standardized chronologies (Table 4). The MS varied less in mountain pine than in European beech, from 0.304 (UG) to 0.365 (PG). The minimum values of MS were found in UG and PE (0.274 and 0.304 , respectively) (Table 4).

In European beech and mountain pine, raw TRW chronologies showed the typical negative exponential trend. Mean standardized chronologies showed similar pattern and synchronization, in both species (Fig. 3). European beech reached MRW increment greater than $1 \mathrm{~mm}$ year $^{-1}$, while mountain pine reached MRW increment of $0.5 \mathrm{~mm} \mathrm{year}^{-1}$.

\subsection{Tree growth response to climate}

Climate influenced tree growth, in both species (Fig. 4).

In European beech, correlation functions showed positive associations between RWI and precipitation in April and May of the current year, in PE, and in August of the previous year, in PG (Fig. 4). Stem radial growth was negatively correlated with maximum temperatures in September and July of the previous and current year and July of the current year, respectively, in UG, whereas it was positively correlated with maximum temperatures in March of the previous year. Stem radial growth was positively influenced by maximum temperatures, in PE, at the end of the growing season (October of the previous and current year) (Fig. 4). Moving correlation functions confirmed the effect of precipitation on stem radial growth, in European beech (Fig. 5). In the last 30 years, precipitation in July of the current year positively influenced stem radial growth, in UG, and precipitation in July of previous year influenced stem radial growth, in PE. Stem radial growth was positively correlated with maximum temperatures in May of the current year, in UG, PG, and BK, but not in PE, between 1988 and 2013 (Fig. 5). In European beech, moving correlation functions also showed positive correlation between RWI and the minimum temperature of August, in PE and UG, in the last 30 years (not shown).

In mountain pine, stem radial growth positively correlated with maximum temperatures in April of the previous year, in UG, and negatively with maximum temperatures in September of current year, in BK (Fig. 4). Stem radial growth was positively correlated with minimum temperatures in April and June of the current year, in UG (Fig. 4). Moving correlation functions did not show positive correlations between RWI and the water availability of the current year, in recent decades, except in August of the previous year, in PG (Fig. 5). Moving correlation functions showed positive correlations between RWI and maximum temperatures in March of the current year (from 1984 until 2013) and of the previous year, in BK (Fig. 5). 
Table 3 Principal structural traits referred to European beech stands in PE-Pescofalcone, UG-Ugni, PG-Piana Grande, BK-Blockhaus

\begin{tabular}{|c|c|c|c|c|}
\hline Site & $\mathbf{P E}$ & UG & PG & BK \\
\hline No. of stumps & 17 & 31 & 8 & 16 \\
\hline No. of stems/individuals & 1.23 & 4 & 5 & 6 \\
\hline No. of trees $h^{-1}$ & 135 & 247 & 64 & 127 \\
\hline Max diameter (cm) & 13 & 34 & 32 & 31 \\
\hline Mean diameter $\pm \mathrm{SD}(\mathrm{cm})$ & $8.5 \pm 1.7$ & $15.4 \pm 5.2$ & $15.3 \pm 6.1$ & $17.3 \pm 6.1$ \\
\hline Average height (m) & 4 & 14.25 & 11.5 & 12.5 \\
\hline
\end{tabular}

\section{Discussion}

Climatic variables affected the growth of mountain pine and European beech at the transitional ecotone between closed forest and pine krummholz of the Majella Massif. Results revealed that the combination of climate and land-cover changes had an impact on tree growth and vegetation shift. However, this effect was species-specific. Species-specific seed production and dispersal agents (wind vs. vertebrates) and the interaction with slope aspect and disturbance legacy (past logging) help explain the spatial and temporal variability in the establishment of European beech and mountain pine across sites. Previous studies revealed krummholz movement upward, which was mainly attributed to land use change, since higher temperature did not elicit increased stem radial growth (Palombo et al. 2014b; Dai et al. 2017), although mountain pine demonstrated to be particularly sensitive to spring temperature. Results confirmed the effects of land use legacies on mountain pine growth dynamics, leading to an upward shift of krummholz vegetation in several mountain ranges across Europe (Jodłowski 2006; Gehrig-Fasel et al. 2007; Mihai et al. 2007; Améztegui et al. 2010; Svajda et al. 2011). Considerable expansion of European beech occurred both into sub-alpine pastures and into the valley (more rapidly) (Van Gils et al. 2008). Bonanomi et al. 2018observed a strong correlation between the European beech tree line, along the Apennines, and with winter and spring temperatures, and summer precipitation, in addition to the association with human disturbance. Yet, this correlation became stronger considering colder sites (high elevation, north face).

In the specific case of Majella Massif, Bonanomi et al. (2018) found both sites with tree lines above $2000 \mathrm{~m}$ a.s.l and sites where the tree line lies below $1200 \mathrm{~m}$ a.s.l., which can hardly be explained by climatic factors and rather points to the legacy of past human activities. Variation in disturbance regime and land cover, related to climate (summer became increasingly drier in the period 1954-2013, in the study area) and land-cover changes (human pressure decreased in the same period), impacted the ecotonal boundaries, creating favorable conditions for the establishment of European beech at higher altitude and of mountain pine at lower altitude. Potential elevation limit of European beech in central Apennines was previously set at $1900 \mathrm{~m}$ a.s.l. (Blasi 2010), thus lower than the locally observed maximum elevation reached by European beech tree line. Indeed, the dense mountain pine krummholz had a facilitative effect on European beech at higher elevation, providing shelter against disturbance and allowing this species to exploit warming temperature. Facilitation has been demonstrated in harsh abiotic conditions and high mountain habitats (Callaway 1998; Callaway et al. 2002; Choler et al. 2001). The protective role of mountain pine on European beech seedlings against biotic and abiotic constraints (e.g., browsing, frost, abrasion) vs. the competition for resources between pine and beech and with
Table 4 Descriptive statistics of tree-ring width for European beech and mountain pine in PE-Pescofalcone, UG-Ugni, PG-Piana Grande, BKBlockhaus. Chronology time span (total years), mean ring width (MRW, mm year ${ }^{-1}$ ), and standard deviation (SD), first-order serial autocorrelation (AC), mean inter-series correlation (Rbar), mean sensitivity
(MS), standard deviation (SD), mean expressed population signal (EPS) (number of years $>0.85$ ). MRW and SD were computed on the raw tree ring chronologies; MS, AC, Rbar, and EPS were computed on the indexed tree ring series (RWI). (EPS = obtained for 30 years with 15 years overlapping; $($ mean $)=$ average of all values $\geq 0.85$ )

\begin{tabular}{|c|c|c|c|c|c|c|c|c|c|c|c|c|c|c|}
\hline \multirow{2}{*}{$\begin{array}{l}\text { Descriptive statistics } \\
\text { Species }\end{array}$} & \multicolumn{2}{|c|}{ Total years } & \multicolumn{2}{|l|}{ MRW } & \multicolumn{2}{|l|}{$\mathrm{AC}$} & \multicolumn{2}{|l|}{ Rbar } & \multicolumn{2}{|l|}{ EPS } & \multicolumn{2}{|l|}{ SD } & \multicolumn{2}{|l|}{ MS } \\
\hline & Beech & Pine & Beech & Pine & Beech & Pine & Beech & Pine & Beech & Pine & Beech & Pine & Beech & Pine \\
\hline PE & 95 & 100 & 0.468 & 0.621 & 0.617 & 0.598 & 0.454 & 0.394 & 0.847 & 0.856 & 0.246 & 0.180 & 0.400 & 0.304 \\
\hline UG & 102 & 98 & 1.228 & 0.645 & 0.568 & 0.700 & 0.487 & 0.270 & 0.912 & 0.535 & 0.211 & 0.176 & 0.274 & 0.323 \\
\hline PG & 118 & 83 & 1.072 & 0.820 & 0.523 & 0.458 & 0.558 & 0.633 & 0.918 & 0.757 & 0.222 & 0.249 & 0.312 & 0.341 \\
\hline BK & 92 & 75 & 1.274 & 0.725 & 0.450 & 0.612 & 0.497 & 0.419 & 0.930 & 0.730 & 0.180 & 0.212 & 0.385 & 0.365 \\
\hline
\end{tabular}


Fig. 3 Mean standardized chronologies of European beech (upper graph) and mountain pine (lower graph) in PE-

Pescofalcone, UG-Ugni, PG-

Piana Grande, BK-Blockhaus. Chronologies were built using the 30 years splined data
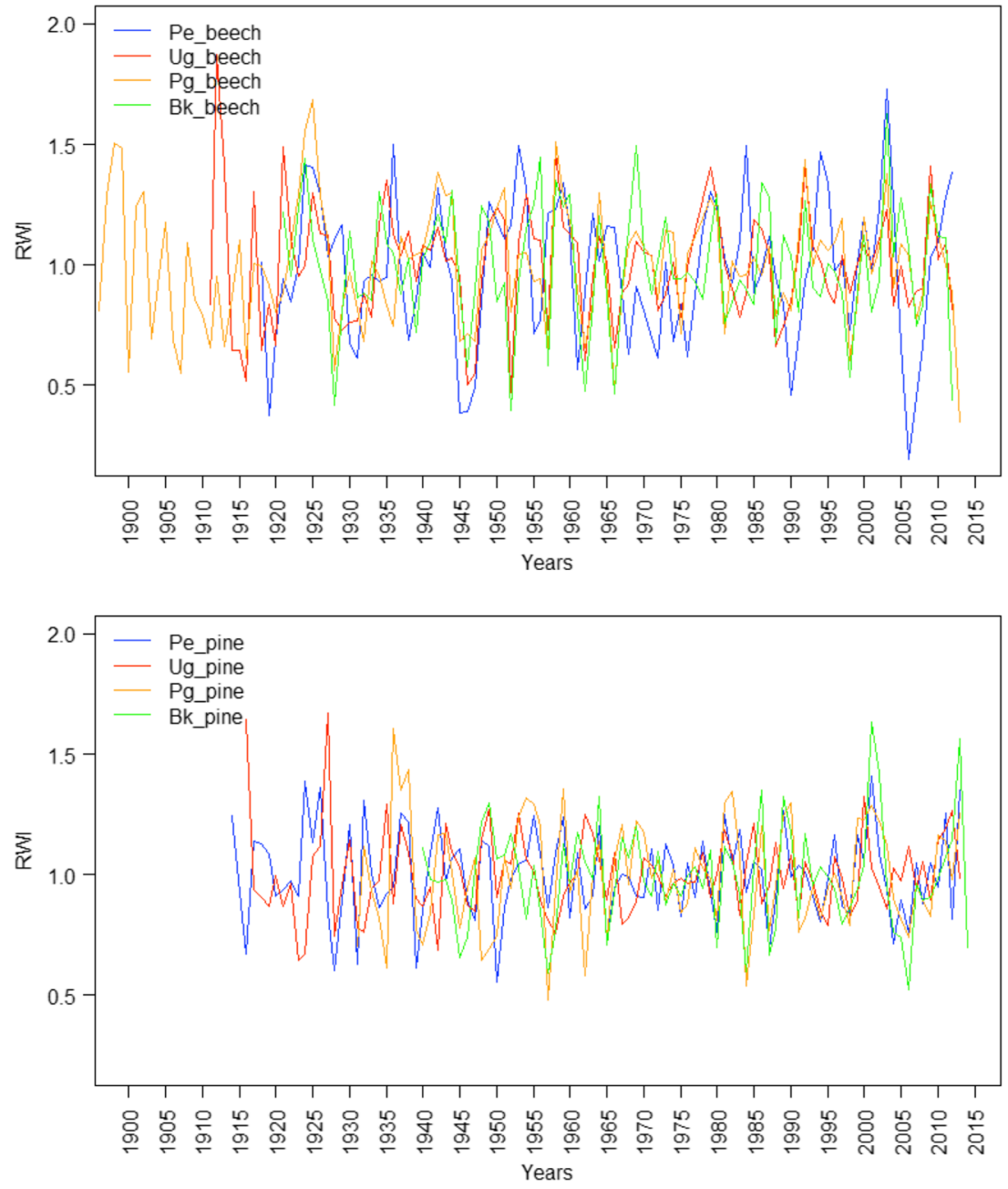

herbaceous vegetation warrants further studies. For instance, a deep snow cover may limit seedling establishment of mountain pine, because soil may thaw before snowmelt (Camarero et al. 2000), though providing shelter against abrasion and desiccation by wind and adequate soil moisture at the start of the growing season to drought-sensitive species.

As expected, the effect of precipitation on tree growth was noticeable for European beech. For instance, in UG, the site at the lowest altitude, higher evaporative demand and lower water supply, especially in July, negatively influenced stem radial growth, in the last 30 years. We may speculate that, at lower elevation, a harsher climate, with greater evaporative demand, would favor the downward shift of mountain pine at the expense of European beech. In these southern populations, soil water supply (early autumn of the current year) and atmospheric evaporative demand (late spring of the current year) are the dominant factors limiting the stem radial growth of European beech (Tognetti et al. 2019). However, the structure of European beech stands in the Majella Massif highlighted a wide intraspecific variability in response to environmental conditions in these altitudinal gradients. European beech grew slowly at the highest elevation, in PE, where climatic and environmental conditions related to the altitude, limited plant growth (2127 $\mathrm{m}$ a.s.1.). As observed by Bonanomi et al. (2020), the highest tree line, found in remote areas without evident anthropogenic disturbance, highlights the general depression of the tree line in central Apennines. Currently, in the Apennines, the average tree line occurs several hundred meters below the potential climatic limit of European beech. Nevertheless, European beech took advantage from the nurse effect exerted by mountain pine and expanded in density. The eldest mountain pines were in PE, where anthropogenic practices were absent because the topography makes it difficult to access the site; yet, mountain pine decreased in density. On the contrary, the youngest mountain pines were in BK, which suffered continuous forest cutting for production of charcoal in the 1950s (low values of MS in Table 2); nevertheless, in BK species-specific density fluctuation followed a pattern similar to that in PE, mountain pine still being the dominant species, whereas, in UG, density fluctuations were stable over time.

An implication of warming temperature and growth response is the simultaneous range expansion of pine shrublands and beech forests upward, which may trigger woodland 

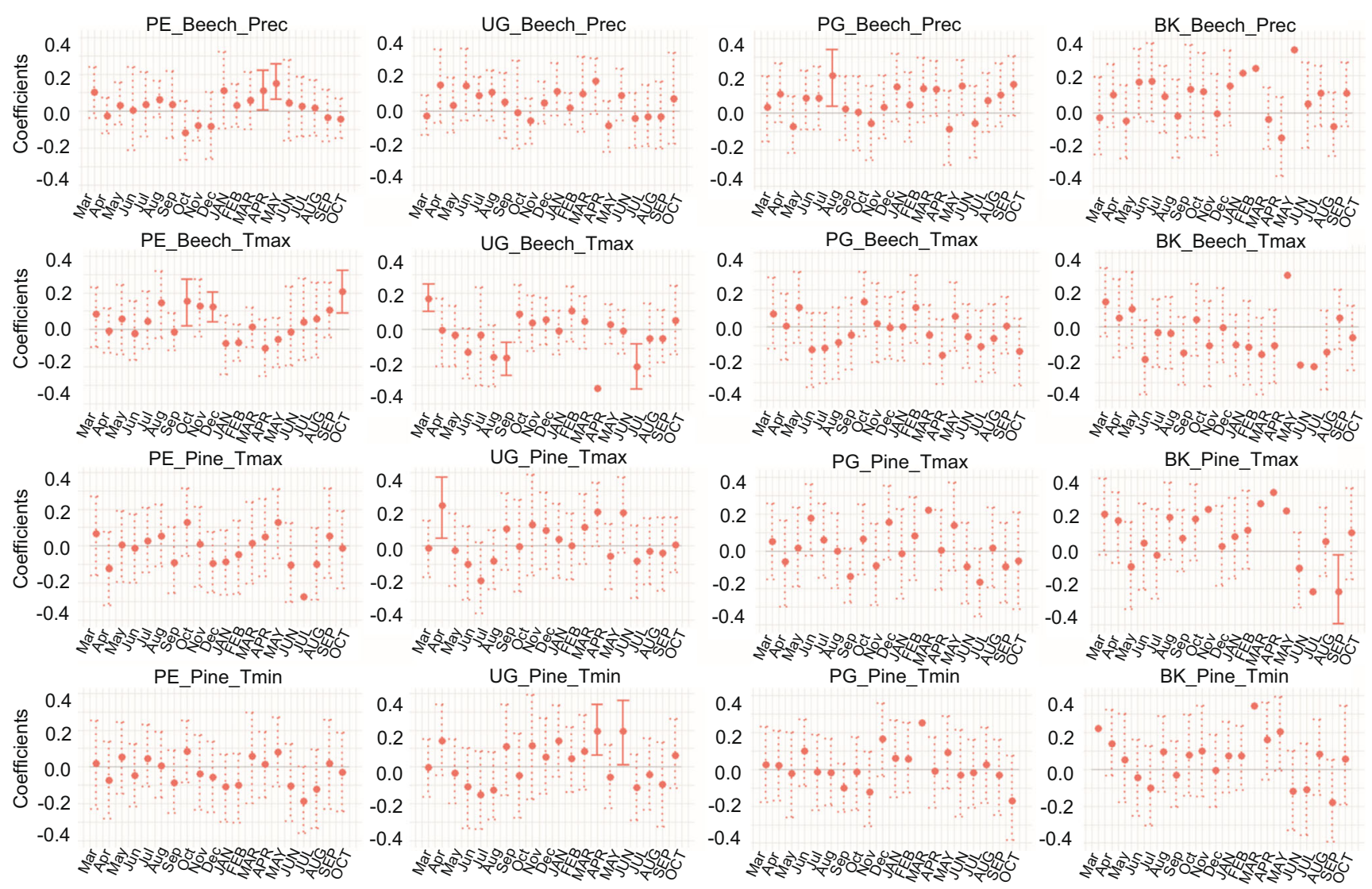

Fig. 4 Bootstrapped response function relating tree-ring growth to precipitation (Prec) and maximum temperature (Tmax), from previous March to current October, for European beech (top-left and top-right, respectively), and to maximum temperature and minimum temperature

(Tmin), for mountain pine (down-left and down-right, respectively), in the period 1901-2013. Months of the previous year are reported in lowercase letters, months of the current year in uppercase letters

encroachment into subalpine pastures (e.g., Dullinger et al. 2004), threatening overall biodiversity. A significant increase of newly established forests in mountain environments has been observed in the Alps and the Apennines (e.g., Bebi et al. 2017; Vacchiano et al. 2017). However, regardless of the absolute changes in elevation of local tree line, downward and upward shifts may occur due to concurring land abandonment and warming temperature, and depending upon species-specific range dynamics. Indeed, warming may induce phenological shifts, potentially impacting European beech at lower elevation (negative effect) and higher elevation (positive effect). Hurdebise et al. (2019), in Belgium, found that increasing temperatures over an 18-year period accelerated plant development and shortened growth duration of European beech. Yet, the start of the dry season in the present Mediterranean mountain forests, anticipating when moving downward, and its relevance may variably affect European beech productivity (Maselli et al. 2014), depending on the elevation. Martinez del Castillo et al. (2018) observed shortening growth duration in drier and warmer environments, with a consequent reduction in the plasticity of European beech, whereas

growing over a longer period might allow co-occurring conifers, namely Scots pine, to compensate drought constraints.

Under higher evaporative demand and lower soil moisture, and consequently shorter growing season, maturation and lignification processes can be impaired, thus affecting the resistance to harsh environmental conditions of the following winter. Again, an earlier onset of leaf unfolding may result in higher sensitivity to spring frost damage in European beech (Bascietto et al. 2018), particularly if compared with mountain pine, because of its vulnerability to winter embolism as a result of freeze-thaw cycles (Borghetti et al. 1993). Nevertheless, Čufar et al. (2015) observed poor relationship between year to year variability in leaf phenology and radial growth, suggesting that earlier leaf unfolding probably does not necessarily increase tree growth rates in European beech. Conversely, when water availability is not limiting European beech development, the duration of the growing season may increase with warming climate, resulting in consistently wider xylem increments (Prislan et al. 2019). In general, RWI was negatively correlated with maximum temperatures in European beech, e.g. during summer months in UG, the site 


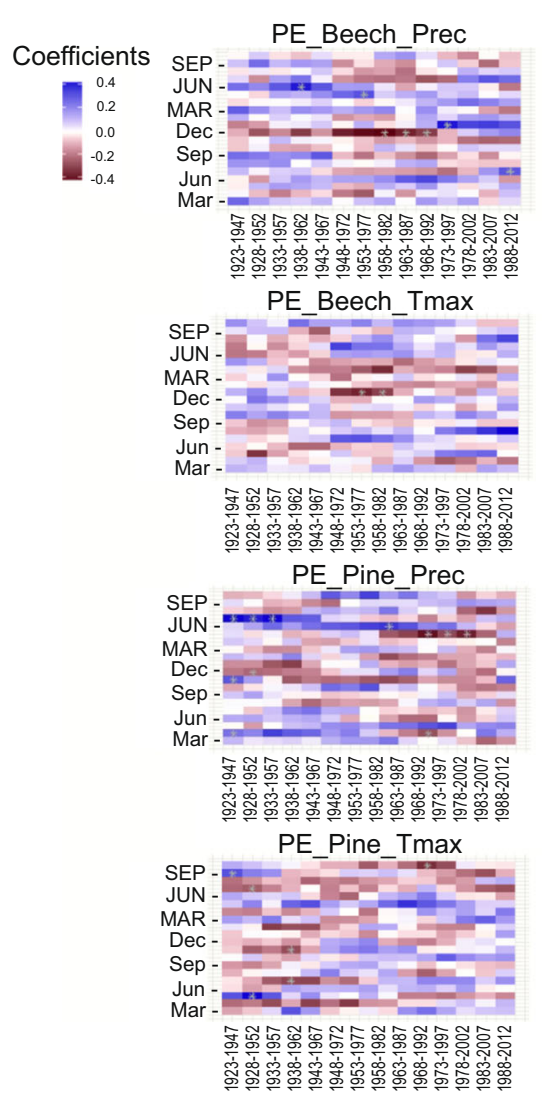

Fig. 5 Moving correlation functions, relating tree-ring growth of European beech, precipitation (Prec) and maximum temperature (Tmax) from previous March to current October (PE-Pescofalcone, UG-Ugni, PG-Piana Grande, BK-Blockhaus). Moving correlation was carried out in windows of 35 years, offset by 5 years. Significant correlations are
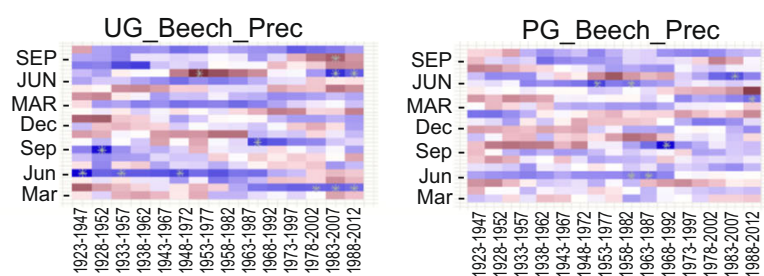

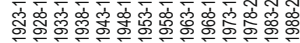
PG_Beech_Tmax

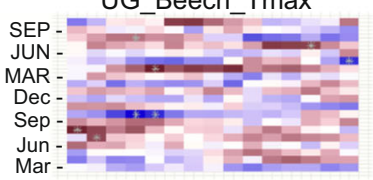

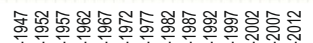

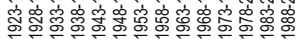
UG Pine Prec

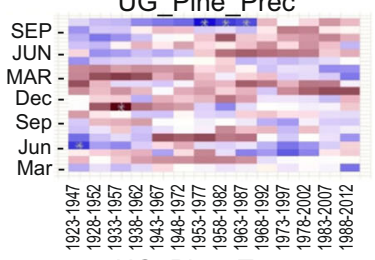
UG_Pine_Tmax

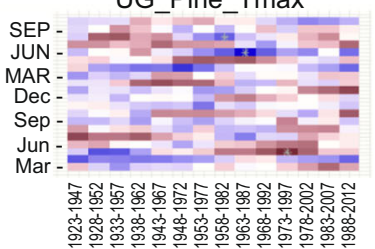

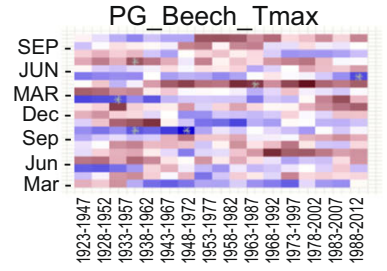

PG_Pine_Prec

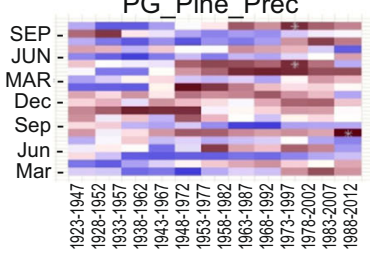
PG_Pine_Tmax

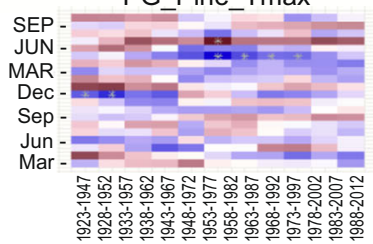

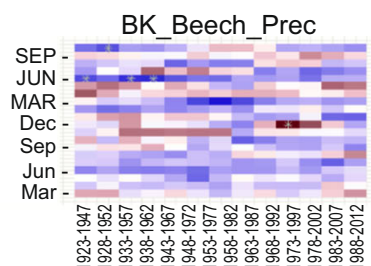

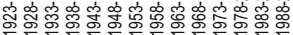

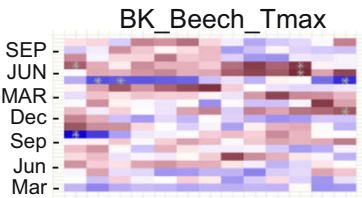

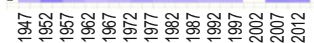

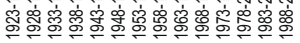

BK_Pine_Prec

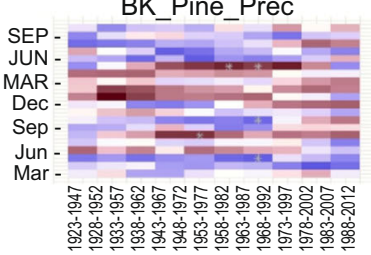

BK_Pine_Tmax

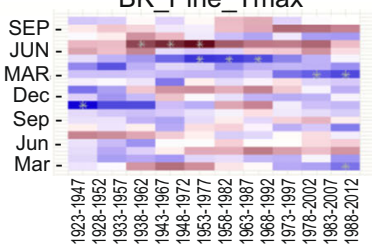

denoted by asterisks. Month of the current year is in capital letters, and that of the previous year is in small letters. The majority of coefficients (coef) display temporal fluctuations. Asterisks indicate windows with significant correlations, positive or negative, for the given variable

at the lowest altitude. Nevertheless, at the highest elevation in $\mathrm{PE}$, the positive correlation between RWI and maximum temperatures in October of the current and previous year would suggest that an elongation of the growing season may occur, with consequent increase in stem radial growth. Palombo et al. (2018), at the tree line on the Majella Massif, observed that the growing season can be consistently longer compared with Alpine environment, lasting from May to October. Dolschak et al. (2019), modeling the water balance of European beech stands, along a gradient of declining annual precipitation, observed that an increase in stand productivity, caused by longer assimilation periods under optimal conditions, could be counterbalanced by soil moisture deficit in the middle of summer.

In PE, anthropic disturbance was less relevant than climatic constraint (accessibility hypothesis). Precipitation influenced tree growth of European beech at the beginning of the growing season (May) and in July (in the last 30 years). This positive correlation can be related to the high altitude of this site, where the species grows at $2127 \mathrm{~m}$ of altitude, under extreme life conditions. European beech has European-wide natural area of distribution, yet ecophysiological and dendroecological studies revealed that populations at the southern margin of its distribution range are sensitive to drought (Peñuelas et al. 2008; Piovesan et al. 2008; Fotelli et al. 2009; Di Filippo et al. 2012; Tognetti et al. 2014). Direct evidence of the impact of summer drought on European beech growth was here provided by the positive correlation between RWI and precipitation in July, even at high elevation. Conversely, in BK, European beech suffered mostly from anthropogenic disturbance, especially during the 1950s, when the forest was completely harvested. In addition to the relevance of the start of dry season on European beech growth (Maselli et al. 2014), increasing damage from late spring frost in recent years may control inter-annual productivity variation of this species at mid elevation, in these Mediterranean mountain environments (e.g., Bascietto et al. 2018; Allevato et al. 2019).

Precipitation did not affect tree growth of mountain pine in the last decades. In PE, the late start of the growing season can be related to the high elevation of the site. Palombo et al. (2014a) observed that temperature and precipitation in April and May played a key role in stem radial growth of mountain pine on the Majella Massif. The evolution of the subalpine ecotone on the Majella Massif was mainly related to spring 
and autumn climatic conditions, whereas, on the Italian Alps, the stem radial growth of mountain pine and its expansion over the current climatic tree line were attributed to the strong influence exerted by high temperatures in May and July and precipitation in June (Pelfini et al. 2006). High temperatures (positive correlation between stem radial growth and maximum temperatures in April of the previous year, in UG, and in March of the previous and current year, in BK, from 1984 to 2013) and significant climate-growth relationships may explain the amelioration of growing conditions for mountain pine over the current climatic situation of the subalpine ecotone, contributing to an increase in the range distribution of this conifer species. Mountain pine is expanding toward higher and lower altitude, re-colonizing large areas formerly grazed and logged, especially where the soil is shallow and rocky. Mountain pine is a pioneer species of avalanche chutes and abandoned pasturelands, threatening endemic herbaceous species and influencing local resource management (Dai et al. 2017). Nevertheless, the balance of competition and facilitation of mountain pine and European beech at the transitional ecotone from the beech closed forest to the pine krummholz vegetation in the Majella Massif is complex, and the effect of one species on another, either positive or negative, can be mediated by other factors (biotic or abiotic). The response of this forest community and ecotonal vegetation to environmental change can, indeed, be influenced by interactions of single climatic and land-cover components with tree species, therefore, impacting biodiversity refugia at high elevation (Stanisci et al. 2005).

Land cover in the middle of the twentieth century showed closed mountain pine krummholz and European beech forest with scattered vegetation. The upward shifts of the pine krummholz above the current tree line appear to be driven by both climate and land-use changes (Palombo et al. 2013; Dai et al. 2017), whereas encroachment of mountain pine downward into the beech forest can be mainly related to the progressive abandonment of traditional forest management. Indeed, the effect of land-cover changes was more important in the zone of transition between European beech closed forest and mountain pine krummholz vegetation than in the upper tree line ecotone (e.g., Treml et al. 2016). Yet, over the last 60 years, European beech forest recovered from clear-cutting during the postwar period. Nowadays, the upward shifts in recruitment of European beech, in contact with mountain pine, take advantage of sheltering from disturbance, disease of mountain pine, and warming temperature.

In the Majella Massif, since 1975, European beech forest cover has expanded into abandoned farm lands and subalpine pastures at a rate of $1.2 \%$ year $^{-1}$ (van Gils et al. 2008), from the contiguous, mid-altitudinal European beech stands. This is consistent with observation on forest expansion at the tree line in the Alps during the twentieth century (Gehrig-Fasel et al. 2007). Forest cover is currently expanding in many mountain areas of the Italian peninsula (Motta et al. 2006; Piermattei et al. 2012; Malandra et al. 2019). Transient forest expansion, due to the process of natural succession causing tree encroachment into abandoned farmland, represents a major land-cover change with tremendous impacts on the mountain landscape. Under climate warming pressure and increasing growing stock, extreme events and associated disturbances (i.e., heat waves, forest fires, wind storms, pest outbreaks) will pose major challenges for climate-smart forest management in decades to come, affecting the stability and productivity of maturing secondary forests in the Apennines.

\section{Conclusions}

The Majella Massif is affected by increasing temperature and land abandonment, in turn determining ecotone dynamics. Climate and land-use changes during the past century prompted a double effect on this Mediterranean mountain environment, facilitating the upward shift of mountain pine and European beech, and creating the opportunity for the encroachment of pine trees into the beech forest, as well as the upward movement of beech trees into the pine krummholz. Results confirmed our first hypothesis that environmental changes increased spatial and temporal dynamics of mountain pine, with facilitation effects on European beech at higher elevation, whereas the competition effects of mountain pine on European beech prevailed at lower elevation, in relation with earlier onset of the growing season and higher risk of late frost damage, confirming our second hypothesis.

With increasing temperature, drought stress might become more common and mountain pine may gain in competitiveness relative to European beech. Different resource use strategies between evergreen and deciduous tree species may result in distinct adaptation potentials to growth-limiting temperatures of high elevation tree lines (e.g., Cong et al. 2018). These species interactions implicate a complex balance of facilitation and competition, which may shift during community development, thus structuring this ecotone through time and space.

This study adds to current knowledge about the evolution of subalpine ecotone of mountain pine and European beech in central Apennines. Encroachment of grasslands and simultaneous downward/upward movement of forest tree species involve species interferences (fine scale) and environmental feedbacks (broad scale) (e.g., Elliott 2011), with differential effects on mountain pine and European beech, and the grassland communities, depending on the ecology of the species. Managing these forests and related changes will require to consider this complexity and an ecosystem-based approach, in practice, the development of a resilient landscape mosaic in this fragile and 
threatened mountain environment, as well as the implementation of effective adaptation strategies.

Acknowledgments The research is linked to activities conducted within the COST (European Cooperation in Science and Technology) Action CLIMO (Climate-Smart Forestry in Mountain Regions - CA15226) financially supported by the EU Framework Programme for Research and Innovation HORIZON 2020. We thank Carabinieri Forestali of Pescara, Caramanico Terme and Palombaro, and the staff of the Majella National Park for their great support during the surveys, Marco Ottaviano and Andrea De Toni (University of Molise), for their suggestions in the photointerpretation analysis.

Data availability The datasets generated during the current study are available from the corresponding author on reasonable request.

\section{Compliance with ethical standards}

The authors declare that they obtained the approval of Carabinieri Forestali for conducting the study in the Oriented Natural Reserves of Orfento Valley and Feudo Ugni.

Conflict of interest The authors declare that they have no conflict of interest.

\section{References}

Allevato E, Saulino L, Cesarano G, Chirico GB, D'Urso G, Falanga Bolognesi S, Rita A, Rossi S, Saracino A, Bonanomi G (2019) Canopy damage by spring frost in European beech along the Apennines: effect of latitude, altitude and aspect. Remote Sens Environ 225:431-440

Alvites C, Battipaglia G, Santopuoli G, Hampel H, Vázquez RF, Matteucci G, Tognetti R (2019) Dendrochronological analysis and growth patterns of Polylepis reticulata (Rosaceae) in the Ecuadorian Andes. IAWA J 40:331-351

Améztegui A, Brotons L, Coll L (2010) Land-use changes as major drivers of mountain pine (Pinus uncinata Ram.) expansion in the Pyrenees. Glob Ecol Biogeogr 19:632-641

Améztegui A, Coll L, Brotons L, Ninot JM (2016) Land-use legacies rather than climate change are driving the recent upward shift of the mountain tree line in the Pyrenees. Glob Ecol Biogeogr 25: 263-273

Ballian, D., Ravazzi, C., de Rigo, D., Caudullo, G., 2016. Pinus mugo in Europe: distribution, habitat, usage and threats. In: San Miguel Ayanz, J., de Rigo, D., Caudullo, G., Houston Durrant, T., Mauri, A. (Eds.), European Atlas of Forest Tree Species. Publ. Off. EU, Luxembourg, pp. e012d81

Bascietto M, Bajocco S, Mazzenga F, Matteucci G (2018) Assessing spring frost effects on beech forests in Central Apennines from remotely-sensed data. Agric For Meteorol 248:240-250

Batllori E, Camarero JJ, Gutierrez E (2010) Current regeneration patterns at the tree line in the Pyrenees indicate similar recruitment processes irrespective of the past disturbance regime. J Biogeogr 37:19381950

Bebi P, Seidl R, Motta R, Fuhr M, Firm D, Krumm F, Conedera M, Ginzler C, Wohlgemuth T, Kulakowski D (2017) Changes of forest cover and disturbance regimes in the mountain forests of the Alps. For Ecol Manag 388:43-56

Blasi C (ed) (2010) La Vegetazione d'Italia con Carte delle serie di vegetazione in scala 1:500.000. Palombi and Partner s.r.1. Editori, Rome, Italy
Blasi C, Di Pietro R, Pelino G (2005) The vegetation of alpine belt karsttectonic basins in the Central Apennines. Plant Biosyst 139:357-385

Bonanomi G, Rita A, Allevato E, Cesarano G, Saulino L, Di Pasquale G, Allegrezza M, Pesaresi S, Borghetti M, Rossi S, Saracino A (2018) Anthropogenic and environmental factors affect the tree line position of Fagus sylvatica along the Apennines (Italy). J Biogeogr 45: 2595-2608

Bonanomi G, Zotti M, Mogavero V, Cesarano G, Saulino L, Rita A, Tesei G, Allegrezza M, Saracino A, Allevato E (2020) Climatic and anthropogenic factors explain the variability of Fagus sylvatica treeline elevation in fifteen mountain groups across the Apennines. For Ecosyst 7:5

Borghetti M, Leonardi S, Raschi A, Snyderman D, Tognetti R (1993) Ecotypic variation of xylem embolism, phenological traits, growth parameters and allozyme characteristics in Fagus sylvatica. Funct Ecol 7:713-720

Briffa KR (1995) Statistical aspects of the interpretation of highresolution proxy climate data: the example of dendro- climatology. In: Von Storch H, Navarra A (eds) Analysis of climate variability: applications of statistical techniques. Springer, Berlin, DE, pp 77-94

Callaway RM (1998) Competition and facilitation on elevation gradients in subalpine forests of the northern Rocky Mountains, USA. Oikos 82:561-573

Callaway RM, Brooker RW, Choler P, Kikvidze Z, Lortie CJ, Michalet R, Paolino L, Pugnaire FI, Newingham B, Aschehoug ET, Armas C, Kikodze D, Cook BJ (2002) Positive interactions among alpine plants increase with stress. Nature 417:844-848

Camarero JJ, Gutiérrez E, Fortin M-J (2000) Boundary detection in altitudinal tree-line ecotones in the Spanish Central Pyrenees. Arct Antarct Alp Res 32:117-126

Camarero JJ, Gutiérrez E, Fortin M-J (2006) Spatial patterns of plant richness across treeline ecotones in the Pyrenees reveal different locations for richness and tree cover boundaries. Global Ecol Biogeogr 15:182-191.

Catonica C, Manzi A (2002) L'influenza della storia climatica e geologica recente sulla Flora d'alta quota dei gruppi montuosi del Gran Sasso e della Majella (Appennino Centrale). Rivista Piemontese di Storia Naturale 23:19-29

Cazzolla Gatti R, Callaghan T, Velichevskaya A, Dudko A, Fabbio L, Battipaglia G, Liang J (2019) Accelerating upward treeline shift in the Altai Mountains under last-century climate change. Sci Rep 9: 7678

Chauchard S, Beilhe F, Denis N, Carcaillet C (2010) An increase in the upper tree-limit of silver fir (Abies alba Mill.) in the Alps since the mid-20th century: a land-use change phenomenon. For Ecol Manag 259:1406-1415

Choler P, Michalet R, Callaway RM (2001) Facilitation and competition on gradients in alpine plant communities. Ecology 82:3295-3308

Cong Y, Wang A, He HS, Yu F-H, Tognetti R, Cherubini P, Wang X, Li M-H (2018) Evergreen Quercus aquifolioides remobilizes more soluble carbon components but less $\mathrm{N}$ and $\mathrm{P}$ from leaves to shoots than deciduous Betula ermanii at the end-season. iForest 11:517-525

Cudlín P, Klopčič M, Tognetti R, Máliš F, Alados CL, Bebi P, Grunewald K, Zhiyanski M, Andonowski V, La Porta N, Bratanova-Doncheva $\mathrm{S}$, Kachaunova $\mathrm{E}$, Edwards-Jonášová $\mathrm{M}$, Ninot JM, Rigling A, Hofgaard A, Hlásny T, Skalák P, Wielgolaski FE (2017) Drivers of treeline shift in different European mountains. Clim Res 73:135-150

Čufar K, De Luis M, Prislan P, Gričar J, Črepinšek Z, Merela M, KajfežBogataj L (2015) Do variations in leaf phenology affect radial growth variations in Fagus sylvatica? Int J Biometeorol 59:11271132

Dai L, Palombo C, van Gils H, Rossiter DG, Tognetti R, Luo G (2017) Pinus mugo Krummholz dynamics during concomitant change in pastoralism and climate in the central Apennines. Mt Res Dev 37: $75-86$ 
Di Filippo A, Biondi F, Maugeri M, Schirone B, Piovesan G (2012) Bioclimate and growth history affect beech lifespan in the Italian Alps and Apennines. Glob Chang Biol 18:960-972

Dolschak K, Gartner K, Berger TW (2019) The impact of rising temperatures on water balance and phenology of European beech (Fagus sylvatica L.) stands. Model. Earth Syst. Environ. 5:1347-1363

Dullinger S, Dirnböck T, Grabherr G (2004) Modelling climate changedriven treeline shifts: relative impacts of temperature increase, dispersal and invasibility. J Ecol 92:241-252

Dullinger S, Dirnböck T, Köck R, Hochbichler E, Englisch T, Sauberer $\mathrm{N}$, Grabherr G (2005) Interactions among tree-line conifers: differential effects of pine on spruce and larch. J Ecol 93:948-957

Elliott GP (2011) Influences of 20th-century warming at the upper tree line contingent on local-scale interactions: evidence from a latitudinal gradient in the Rocky Mountains. USA Global Ecol Biogeogr 20:46-57

Fotelli MN, Nahm M, Radoglou K, Rennenberg H, Halyvopoulos G, Matzarakis A (2009) Seasonal and interannual ecophysiological responses of beech (Fagus sylvatica) at its south-eastern distribution limit in Europe. For Ecol Manag 257:1157-1164

Gehrig-Fasel J, Guisan A, Zimmermann NE (2007) Treeline shifts in the Swiss Alps: climate change or land abandonment? J Veg Sci 18: 571-582

Gottfried M, Pauli H, Futschik A, Akhalkatsi M, Barancok P, Benito Alonso JL, Coldea G, Dick J, Erschbamer B, Fernandez Calzado MR, Kazakis G, Krajci J, Larsson P, Mallaun M, Michelsen O, Moiseev D, Moiseev P, Mo-lau U, Merzouki A, Nagy L, Nakhutsrishvili G, Peder-sen B, Pelino G, Puscas M, Rossi G, Stanisci A, Theurillat JP, Tomaselli M, Villar L, Vittoz P, Vogiatzakis I, Grabherr G (2012) Continent-wide response of mountain vegetation to climate change. Nat Clim Chang 2:111-115

Guiot J (1991) The bootstrapped response function. Tree-Ring Bull 51: $39-41$

Harsch MA, Hulme PE, Mc Glone MS, Duncan RP (2009) Are treelines advancing? A global meta-analysis of treeline response to climate warming. Ecol Lett 12:1040-1049

Holmes RL (1983) Computer assisted quality control in tree-ring dating and measurement. Tree-Ring Bull 43:69-78

Houston Durrant T, de Rigo D, Caudullo G (2016) Fagus sylvatica and other beeches in Europe: distribution, habitat, usage and threats. In: San Miguel Ayanz J, de Rigo D, Caudullo G, Houston Durrant T, Mauri A (eds) European Atlas of Forest Tree Species. Publ. Off. EU, Luxembourg, p e012b90

Hurdebise Q, Aubinet M, Heinesch B, Vincke C (2019) Increasing temperatures over an 18 -year period shortens growing season length in a beech (Fagus sylvatica L.)-dominated forest. Ann For Sci 76:75

IPCC (2013) Summary for policymakers. In: Stocker TF, Qin D, Plattner GK, Tignor M, Allen SK, Boschung J, Nauels A, Xia Y, Bex V, Midgley PM (eds) Climate Change 2013. The Physical Science Basis. Contribution of Working Group I to the Fifth Assessment Report of the Intergovernmental Panel on Climate Change. Cambridge University Press, Cambridge

Jodłowski M (2006) Geographical controls on the course of the upper mountain pine (Pinus mugo) limit in the Tatra mts. Ekológia 25: $105-114$

Körner C, Paulsen J (2004) A world-wide study of high altitude treeline temperatures. J Biogeogr 31:713-732

Lenoir J, Gégout JC, Marquet PA, De Ruffray P, Brisse HA (2008) significant upward shift in plant species optimum elevation during the $20^{\text {th }}$ century. Science $320: 1768-1771$

Malandra F, Vitali A, Urbinati C, Weisberg PJ, Garbarino M (2019) Patterns and drivers of forest landscape change in the Apennines range. Italy. Reg Environ Chang 19:1973-1985

Martinez del Castillo E, Prislan P, Gričar J, Gryc V, Merela M, Giagli K, de Luis M, Vavrčík H, Čufar K (2018) Challenges for growth of beech and co-occurring conifers in a changing climate context. Dendrochronologia 52:1-10

Maselli F, Cherubini P, Chiesi M, Gilabert MA, Lombardi F, Moreno A, Teobaldelli M, Tognetti R (2014) Start of the dry season as a main determinant of inter-annual Mediterranean forest production variations. Agric For Meteorol 194:197-206

Mihai B, Savulescu I, Sandric I (2007) Change detection analysis (19862002) of vegetation cover in Romania. Mt Res Dev 27:250-258

Mitchell TD, Jones PD (2005) An improved method of constructing a database of monthly climate observations and associated highresolution grids. Int J Climatol 25:693-712

Motta R, Morales M, Nola P (2006) Human land use, forest dynamics and tree growth at the treeline in the Western Italian Alps. Ann For Sci 63:739-747

NOAA 2019 National Centers for Environmental Information, State of the Climate: Global Climate Report for Annual 2018, published online January 2019, retrieved on December 9, 2019 from https:// www.ncdc.noaa.gov/sotc/global/201813.

Nolè A, Rita A, Ferrara AMS, Borghetti M (2018) Effects of a large-scale late spring frost on a beech (Fagus sylvatica L.) dominated Mediterranean mountain forest derived from the spatio-temporal variations of NDVI. Ann For Sci 75:83

Palombo C, Chirici G, Marchetti M, Tognetti R (2013) Is land abandonment affecting forest dynamics at high elevation in Mediterranean mountains more than climate change? Plant Biosyst 147:1-11

Palombo C, Marchetti M, Tognetti R (2014a) Mountain vegetation at risk: current perspectives and research needs. Plant Biosyst 148: $35-41$

Palombo C, Battipaglia G, Cherubini P, Chirici G, Garfi V, Lasserre L, Lombardi F, Marchetti M, Tognetti R (2014b) Warming-related growth responses at the southern limit distribution of mountain pine (Pinus mugo Turra ssp. mugo). J Veg Sci 25:571-583

Palombo C, Fonti P, Lasserre B, Cherubini P, Marchetti M, Tognetti R (2018) Xylogenesis of compression and opposite wood in mountain pine at a Mediterranean treeline. Ann For Sci 75:93

Pelfini M, Leonelli G, Santilli M (2006) Climatic and environmental influences on mountain pine (Pinus montana Miller) growth in the central Italian Alps. Arct Antarct Alp Res 38:614-623

Peñuelas J, Hunt JM, Ogaya R, Jump AS (2008) Twentieth century changes of tree-ring $\delta^{13} \mathrm{C}$ at the southern range-edge of Fagus sylvatica: increasing water use efficiency does not avoid the growth decline induced by warming at low altitudes. Glob Chang Biol 14: 1076-1088

Pezzi G, Bitelli G, Ferrari C, Girelli VA, Gusella L, Masi S, Mognol A (2007) Pattern temporale del limite altitudinale dei boschi di faggio nell'Appennino settentrionale. Un'analisi di dati fotogrammetrici. Forest@ 4:79-87

Piermattei A, Renzaglia F, Urbinati C (2012) Recent expansion of Pinus nigra Arn. above the timberline in the central Apennines,Italy. Ann For Sci 69:509-517

Piovesan G, Biondi F, Di Filippo A, Alessandrini A, Maugeri M (2008) Drought-driven growth reduction in old beech (Fagus sylvatica L.) forests of the central Apennines, Italy. Glob Chang Biol 14:12651281

Prislan P, Gričar J, Čufar K, de Luis M, Merela M, Rossi S (2019) Growing season and radial growth predicted for Fagus sylvatica under climate change. Clim Chang 153:181-197

Rangwala I, Miller JR (2012) Climate change in mountains: a review of elevation-dependent warming and its possible causes. Clim Chang 114:527-547

Schweingruber FH (1988) Tree rings: basics and applications of dendrochronology. Kluwer Academic, Dordrecht, NL

Speed JDM, Austrheim G, Hester AJ, Mysterud A (2010) Experimental evidence for herbivore limitation of the tree- line. Ecology 91:3414 3420. https://doi.org/10.1657/1938-4246-46.3.535 
Stanisci A, Pelino G, Blasi C (2005) Vascular plant diversity and global change in central Apennine (Italy). Biodivers Conserv 14:13011318

Svajda J, Solár J, Janiga M, Buliak M (2011) Dwarf pine (Pinus mugo) and selected abiotic habitat conditions in the western Tatra Mountains. Mt Res Dev 31:220-228

Tognetti R, Palombo C (2013) Take a tree to the limit: the stress line. Tree Physiol 33:887-890

Tognetti R, Lombardi F, Lasserre B, Cherubini P, Marchetti M (2014) Tree-ring stable isotopes reveal twentieth-century increases in water-use efficiency of Fagus sylvatica and Nothofagus spp. in Italian and Chilean mountains. PLoS One 9:113-136

Tognetti R, Lasserre B, Di Febbraro M, Marchetti M (2019) Modeling regional drought-stress indices for beech forests in Mediterranean mountains based on tree-ring data. Agric For Meteorol 265:110-120

Treml V, Šenfeldr M, Chuman T, Ponocná T, Demková K (2016) $20^{\text {th }}$ century treeline ecotone advance in the Sudetes Mountains (Central Europe) was induced by agricultural land abandonment rather than climate change. J Veg Sci 27:1209-1221
Vacchiano G, Garbarino M, Lingua E, Motta R (2017) Forest dynamics and disturbance regimes in the Italian Apennines. For Ecol Manag 388:57-66

van Gils H, Batsukh O, Rossiter D, Munthali W, Liberatoscioli E (2008) Forecasting the pattern and pace of Fagus forest expansion in Majella National Park,Italy. Appl Veg Sci 11:539-546

Walther GR, Beißner S, Burga CA (2005) Trends in the upward shift of alpine plants. J Veg Sci 16:541-548

Wigley TML, Briffa KR, Jones PD (1984) On the average value of correlated time series, with applications in dendroclimatology and hydrometeorology. J Clim Appl Meteorol 23:201-213

Zang C, Biondi F (2013) Dendroclimatic calibration in R: the bootRes package for response and correlation function analysis. Dendrochronologia 31:68-74

Publisher's note Springer Nature remains neutral with regard to jurisdictional claims in published maps and institutional affiliations. 